\title{
O DIREITO FUNDAMENTAL DA CIDADANIA E A PROTEÇÃO DO MIGRANTE NO SISTEMA JURÍDICO BRASILEIRO
}

\author{
THE FUNDAMENTAL RIGHT OF CITZENSHIP AND \\ THE PROTECTION OF MIGRANT IN THE BRAZILIAN \\ JURIDICAL SYSTEM
}

Carlos Eduardo de Abreu Boucault ${ }^{1}$

UNESP

\section{Resumo}

O presente trabalho tem por fim analisar os aspectos referentes aos princípios de proteção ao migrante na legislação brasileira em vigor, conforme uma visão cosmopolita do fenômeno migratório no campo dos Direitos Humanos e os meios de aplicação da Lei de Migrações pela estrutura judicial e administrativa do sistema jurídico brasileiro.

Palavras-chave

Migrações. Lei de Imigração. Cosmopolitismo

\section{Abstract}

In order to review the brazilian legal systtem concerning migration law about the promotion of Human Rights, this work. focuses the application of rules and principles settled by the new law of migrations as well the model of implementation politics and administrative means of social rights protetion.

Keywords

Migrations. Law of Migration. Cosmopolitism

\section{INTRODUÇÃO}

${ }^{1}$ Professor da Universidade Estadual Paulista "Júlio de Mesquita Filho" - UNESP, campus de Franca - SP e Professor titular do curso de Direito da Fundação Armando Álvares Penteado - FAAP - São Paulo. Doutor em Direito pela USP. 
Tanto a visão kantiana da "Paz Universal" como a prospeção teórica de Carl von Savigny edificando uma modificação profunda na órbita das relações internacionais resultam na concepção de um novo "ethos" solene a condição do cidadão estrangeiro no mundo contemporâneo, particularmente, no que se refere ao fluxo das migrações em sua variegada tipologia institucional.

Em que pese os avanços no plano das iniciativas de proteção do estrangeiro no âmbito normativo convencional e da teoria cosmopolita que caracteriza o século XXI, convém secundar-se o papel do Estado na condução de políticos restritivas à imigração e as formas de controle da entrada de pessoas no território nacional, observando-se os limites e as práticas de flexibilização desse cenário no contexto da soberania estatal e das pulsões nacionalistas que protagonizam atos de violência e de agressão ao estrangeiro, na temática da equiparação de direitos entre cidadãos imigrantes e nacionais.

No que pertine ao direito brasileiro, este trabalho centra sua análise em alguns tópicos disciplinados pela nova lei de migração que entrou em vigor em novembro de 2017 - Lei $\mathrm{n}^{\circ} 13.445$, revogando o decreto lei 6815, de 1980, o Estatuto do estrangeiro, concebido no modelo da ideologia da segurança nacional do regime militar vigente de 1964 a 1982. Sob esse aspecto, é inegável a mudança no sistema jurídico embasado nos princípios da Constituição Federal de 1988 que consagra a importância das normas oriundas de tratados e convenções internacionais pautadas no plano eminentemente ético dos Direitos Humanos.

Ademais, do ponto de vista histórico, não se pode ignorar a presença de elementos sociojurídicos da formação cultural do Brasil, como país de imigração, além de se verificar os estereótipos da imigração na vertente antropológica da questão, em face do tipo de estrangeiro, o perfil do imigrante sujeito às modalidades de vistos a que estejam sujeitos e as formas de sua saída ou de ingresso em território nacional, fatores que revelam ainda um traço acentuadamente policialesco na efetivação dessas 
normas pelas autoridades responsáveis pela polícia da fronteira, marítima e aeroportuária.

Igualmente necessária é a análise da tramitação legislativa da lei de migração atual e a influência que essa fonte normativa recebeu da concepção argentina no âmbito do Mercosul, visualizando-se a tibieza do governo brasileiro em adotar medidas mais concretas na eliminação de diferenças entre nacionais e imigrantes, principalmente, na formulação de políticas públicas tendentes a flexibilizar critérios de recepção de imigrantes em território brasileiro.

Afigura-se oportuno o exame dos direitos do cidadão estrangeiro quanto a determinadas garantias constitucionais, dentre elas, a liberdade, tão violada no período do governo militar, em que o caso do Padre Vitor Miracapillo é o exemplo eloquente da ação nociva de órgãos estatais, violando o princípio dos Direito Humanos. Esse episódio resultou na expulsão do padre Vitor, mediada por uma hermenêutica autoritária da legislação sobre o regime jurídico do estrangeiro e as atividades de subversão e suas nocividades ao Estado brasileiro.

A partir da intensificação de conflitos no mundo contemporâneo, o fluxo de pessoas, seja na condição de migrantes, refugiados, deslocados, em situação de vulnerabilidade, de precariedade econômica, ambiental requer uma ação contínua e sólida dos Estados e de organizações Internacionais e demais instituições protetivas dos direitos de migrantes com o objetivo de integrar o diálogo, entre as normas jurídicas domésticas e internacionais em benefício dos cidadãos, infundindo um sentimento de solidariedade e de integração de políticas e práticas institucionais para promoção dos direitos do cidadão estrangeiro.

$\mathrm{Na}$ mesma linha, deve-se, da mesma forma reconhecer a contribuição das normas de Direito Internacional Privado dinamizando o Universo dos Direitos Humanos sob a esfera dos fluxos internacionais, flexibilizando princípios e institutos em prol do migrante em sua mobilidade territorial. 


\section{INTEGRAÇÃO E ASSIMILAÇÃO DOS GRUPOS MIGRATÓRIOS: A DES(CONSTRUÇÃO) DE IDENTIDADES}

Jean B. Duroselle ${ }^{2}$ em algumas passagens de sua obra registra a condição do estrangeiro no universo histórico como se segue: "O estrangeiro não é o inimigo Para Caim, o inimigo é Abel, seu irmão. E, inversamente, o estrangeiro é muitas vezes tratado como amigo. Ulisses, em seu périplo, é algumas vezes muito bem recebido. A paixão pelo poder interno pode levar a uma facção a considerar o estrangeiro como um amigo, sendo inimigo a facção rival. " [...] "Por outro lado, o estrangeiro, amigo ou inimigo, é um homem diferente e, consequentemente, com comportamento estranho, até imprevisível. É o homem que introduz o aleatório." Tais observações aludem ao contato cultural de matrizes diversas que perpassam a experiência do idioma, da religião, da formação familiar, do nível de escolaridade e, nesse diapasão, às implicações políticas decorrentes da entrada do cidadão imigrante num determinado território e de sua permanência temporária ou não, conforme a natureza do visto ou de atos administrativos que regulem a legalidade da permanência do imigrante e de sua família no estado receptor. Nesse sentido, as dificuldades de adaptação, de socialização de grupos étnicos que se enquadram na condição de imigrantes se avolumam em face das condições precárias de sua instalação no estado de acolhimento, desde a existência de abrigos, alojamentos, moradia e da atividade laboral.

Outra dimensão importante nesse contexto é a inclusão educacional, principalmente de crianças e adolescentes, que, além do elemento idiomático, enfrentam o impacto de uma cultura diferente e não consoante ao referencial originário de sua formação. São processos traumáticos que essas comunidades vivenciam pois seu deslocamento e

2 Duroselle, Jean B. Todo Império perecerá - Teoria das Relações Internacionais. Trad. Ana Eliza S. de Siqueira Magalhães. Brasília, EdUnb, 2000, p.50 
mobilidade são involuntários, seja como deslocado, refugiado, em situação de vulnerabilidade sócio-econômica e, também, política, como o asilo e o refúgio, ou decorrente de guerras, revoluções e catástrofes naturais ou ambientais. $\mathrm{E}$ os conflitos recentes na ordem internacional em pontos continentais distintos, como a guerra civil na Síria, a crise no Governo da Venezuela exigem na perspectiva da epistemologia histórica uma diretiva antropológica em direção aos sinais identitários do imigrante e de sua inserção no território do estado de acolhimento, perpassando a tramitação do processo de concessão de visto pelas autoridades diplomáticas ou regularização de cidadãos oriundos de situação de clandestinidade, vitimização por transporte ilegal de pessoas, como indivíduos procedentes de países africanos, e nacionais do México que pretendem ingressar em território norte-americano.

Com respeito a essa abordagem é ilustrativa a análise de Kathryn Woodward sobre a questão da identidade e a diferença na construção do perfil do estrangeiro e de sua inserção em outra cultura, a partir de elementos simbólicos que configuram a preservação de uma "identidade" criada por representações simbólicas estabelecidas pela cultura e os mecanismos de significação que ela produz no sentido de integrar aqueles que pertence ao grupo étnico local e o que dele não faz parte. $\mathrm{O}$ adágio "Pas min éllinas, barbarós" - já continha o elemento da estraneidade e o conceito de pertencimento, pois "bárbaro" é o "não-ateniense", aquele que se sujeita a qualquer lei. Na verdade, a identidade como um princípio de exclusão do "outro", "estranho" e "imprevisível" constitui-se num valor consagrado por práticas nacionalistas e xenófobas, enfatizadas pelos estados, criando uma comunidade que se deseja homogênea, que compartilha valores estáveis consolidados pelas forças institucionais. E a esse conjunto de idealizações acrescem-se os vetores da religião, da raça, do gênero que na pauta dos Direitos Humanos esboroam sentimentos de discriminação, fragilizando esses modelos autoritários e nacionalistas do século XXI. A mobilização política de grupos e de organizações singulares buscam a solidariedade entre os povos e a proteção a grupos socialmente 
mais vulneráveis como os imigrantes que, em outras circunstâncias, não abandonariam seu país de origem. Todavia, a autora ${ }^{3}$ referida, assim analisa: "As identidades são fabricadas por meio da marcação da diferença. Essa marcação da diferença ocorre tanto por meio de sistemas simbólicos de representação quanto por meio de formas de exclusão social. A identidade, pois, não é o oposto da diferença: a identidade depende da diferença. Nas relações sociais, essas formas de diferença - a simbólica e a social - são estabelecidas, ao menos em parte, por meio de sistemas classificatórios. Um sistema classificatório aplica um princípio de diferença a uma população de uma forma tal que seja capaz de dividi-la (e a todas as suas características) em ao menos dois grupos oportunos - nós/eles (por exemplo, servos e croatas); eu/outro."

As posições sociais pesam no ingresso do imigrante em território estrangeiro, particularmente, no campo da atividade laboral. Via de regra, o imigrante traz em sua formação escolar um nível de conhecimento superior ao do brasileiro comum, pois seus países oferecem um sistema de ensino e de formação profissional mais eficiente. Falam língua estrangeira, falam com propriedade e tem redação textual adequada ao nível escolar, e, dessa forma, podem ocupar o posto de trabalho de um nacional. Esse fenômeno ocorreu com os haitianos e, ocorre, também com os imigrantes venezuelanos, sírio-, libaneses, ugandenses, moçambicanos, que, exercem, na maioria das vezes, atividades subalternas em relação à formação escolar, ou de trabalho precário.

A Europa contemporânea se ensurge, em muitos países, contra a política migratória e as manifestações populares e de grupos se caracterizam pelo repúdio ao ingresso de imigrantes em seu território, marcadamente, pelo fator religioso, associado ao terrorismo, relacionado aos nacionais de países árabes e, de modo específico à cultura islâmica. Em

${ }^{3}$ Silva, Tomaz T. (org), Hall, Stuart Woodward, Kathryn. Identidade e Diferença. A perspective dos Estados Culturais. Traduções: Tomaz T. da Silva. Petrópolis, Ed. Vozes. 
países cuja economia é mais deficitária, como a Itália, o imigrante representa um risco à mão-de-obra e ao trabalho destinados a um cidadão italiano. E, ainda, manifestações xenófobas se exacerbam como grupos neo-nazistas.

Entretanto, as políticas públicas de governos engajados na vertente democrática e na proteção aos direitos e garantias do ser humano, irmandades com a prática internacional em sua múltipla produção normativa em prol do fomento aos Direitos Humanos, convergem para uma nova dinâmica do Direito Internacional voltada para a reestruturação da ação estatal e de instituições governamentais, comunitárias e nãogovernamentais que se destine a propiciar um tratamento equânime e humano aqueles que não tem como permanecer em sua pátria, por razões alheias a sua vontade. Todavia, essa expectativa não perde de vista as formas de controle que o Estado exerce no processo de acolhimento de imigrantes e de seu interesse na retirada ou saída dessa categoria de seu espaço físico, há limites da ideologia nacional, substantivados no princípio da defesa nacional e da soberania política. A visão de integração de imigrantes não pode redundar em um cosmopolitismo superficial e ilusório, como fundamento da ordem política internacional. A questão é que o fenômeno da "globalização" arrefece as estruturas do estado clássico e de comunidades tradicionais, transformando as divisões sociais pelo significado cultural do movimento de transnacionalização econômica marcada pelos fluxos migratórios e as consequências no contexto de identidades, diferenças étnicas, a partir da recepção do migrante pelo ambiente local de acolhimento. Consoante esse cenário, Igor J. Renó Machado ${ }^{4}$ atenta para a fragilização dos mecanismos institucionais e jurídicos na implementação de instrumentais políticas públicas ao questionar sobre qual o perfil de estrangeiro, o olhar do legislador contempla em prol da solidariedade para com os valores do cosmopolitismo consagrado por I. Habermas.

${ }^{4}$ Machado, J.. I. Renó. O imigrante e o Estado da diferença. Cátedra da UNESCO. 2015. Memorial da América Latina - S.Paulo 


\section{A IMPLEMENTAÇÃO DE PRÁTICAS ADMINSTRATIVAS DA LEI DE 13.445, DE 2017}

A análise desenvolvida nesse tópico assinala a transição da lei 6815 de 1980, conhecida como Estatuto do estrangeiro e a entrada em vigor da nova Lei de Migrações no ano de 2017, examinando-se os registros em que se verifica os avanços que o novo diploma legal carreou para a uma nova configuração de política migratórias na institucionalização de práticas administrativas e judiciais na proteção ao migrante e ao reconhecimento da cidadania plasmada na agenda dos Direitos Humanos tanto sob a perspectiva democrática da Constituição Federal como na dimensão da igualdade no sentimento de pertences e na condição de cidadãos livres.

No projeto convencional que resultou na vigência da Lei brasileira de Migração, notícia Ludmila A. Culpi ${ }^{5}$ que a formação de políticas migratórias engendrada nos antecedentes normativos teve como modelo a lei migratória argentina, pela articulação do MERCOSUL, observando que a lei argentina se caracteriza por uma pauta mais renovadora e consentânea com os aspectos sócio-jurídicos da promoção dos valores universais dos direitos dos migrantes, essencialmente centrada nos Acordos de Residência do Mercosul de 2002. Reconhece, entretanto, a autora que o direito brasileiro consubstanciou a temática migratória no plano dos Direitos Humanos, em detrimento do modelo do princípio da Segurança Nacional ideado pelo governo militar. Assis, direitos e garantias foram assegurados como residência, a reunificação familiar, o acesso à justiça.

Certamente a transição de modelos de política migratória não se operacionalizou de forma imediata, ainda que se considere os

\footnotetext{
${ }^{5}$ Culpi, Ludmila A. In http://www.luhumanas.ufpr.br/portal/nepri/files. 2012/04 novalei-de-migração $\% \mathrm{C} \% \mathrm{~A} 7 \% \mathrm{C} 3 \%$ BJ es-brasileira Inspira $\% \mathrm{C} \% . \mathrm{A} 7 \% \mathrm{C} 3 \mathrm{y} \% .30$-no-modeloda-lei-argentina pdf A 30-no
} 
fundamentos da Constituição Federal de 1988 expresso pelos princípios da cidadania, da dignidade da pessoa humana, a prevalência dos direitos humanos, a cooperação entre os povos para o progresso da humanidade e a igualdade entre brasileiros e estrangeiros estabelecida no "caput" do artigo $5^{\circ}$. Acresça-se o universo do Direito Internacional, pelas fontes convencionais, de eloquente dicção conforme o artigo $2^{\circ}$ do artigo $5^{\circ}$, em que emergem a Declaração Universal dos Direitos Humanos, o Pacto Internacional dos Direitos Civis e Políticos. No âmbito da América Latina, a OEA, a Declaração de Cartagena e os processos revisionais e consultivos tem dinamizado a questão migratória, assim como o bloco do Mercosul e a Declaração de São José sobre Refugiados e Pessoas Deslocadas. Nessa perspectiva, verifica-se que a lei de estrangeiros 6815/80 continuou em vigor até 2017, embora muitas de suas disposições tenham perdido a eficácia normativa por influxo da prática da hermenêutica dos tribunais e de legislação extravagante, como a lei 9474, de 1997 que regulava medidas de retirada compulsória de estrangeiros do território nacional, nas modalidades de deportação, expulsão, extradição e de repatriação.

De acordo com esse contexto normativo, a "práxis" administrativa de controle de entrada, permanência e retirada de estrangeiros no território nacional permaneceu adstrita à estrutura policial e consular em face dos procedimentos regulamentares para a concessão de Vistos em todas suas modalidades. Como sinalizam Dolowiz e Marsh ${ }^{6}$, a legislação e regramentos aplicáveis à condição jurídica do estrangeiro e, particularmente, como migrante, estabelecem um mecanismo intensificado por uma burocracia complexa e aleatória, a critério arbitrário dos agentes incumbidos da concretização do processo de entrada e de permanência no território brasileiro, mediante composição de arranjos administrativos, exigências documentais não provistas em lei, relevando-se ainda o problema

${ }^{6}$ Dolowiz, D. e Marsh, D. "The future of the Policy Transfer research. In: Political Studies Review, 2012, v.10, p.369-345 
do idioma que o migrante não assimila, durante o comparecimento aos órgãos da Polícia Federal. Diante de tal problemática, o gerenciamento da política migratória em sua consecução administrativa situa-se a cargo do setor policial, desde as unidades da Fronteiras, Marítimas, Aéreas, consulares e Ministério da Justiça.

Ao contrário da busca pela ampliação dos diversos instrumentos de efetividade dos princípios de proteção ao migrante, como ser humano, seja qual for a qualificação jurídica de sua estraneidade, como apátrida, refugiado, deslocado, residente temporário ou permanente, a medida de controle migratório no cenário contemporâneo tem se revelado restritivas e discriminatórias, com em países europeus, ressuscitando sentimentos xenófobos e segregacionistas. Em elucidativo trabalho, sob o enfoque do cosmopolitismo de nossa época, Marcelo de Lima ${ }^{7}$ registra a fragilização da cultura nacionalista decorrente do modelo expansionista europeu do século XIX, contrapondo-lhe o sentimento de alijamento do estrangeiro em face do descortínio de um novo dimensionamento das migrações e o direito à igualdade de oportunidades que o cidadão estrangeiro tem, diante de dificuldades em seu país, mas, também, pela contribuição que pode oferecer pela força de trabalho, pelo viés cultural de sua história no locus de sua permanência, porquanto, o ideal democrático persegue a garantia dos direitos civis, políticos, econômicos e sociais, diluindo a rigidez anacrônica de hierarquias sociais, infundindo nos Estados o dever de recepcionar cidadãos pelos compromissos éticos assumidos na seara das relações internacionais. A visão desse autor se coaduna com a observação do congolês Jean Katumba Mulondayi ${ }^{8}$, que sofreu tortura em seu país e, atualmente, preside a África do Coração, federação de imigrantes: "Ninguém nasce refugiado; a gente se torna refugiado para salvar a nossa vida. Mas, com em um jogo de futebol, não podemos ficar só no lugar da

7 Lima, Marcelo de. O Estado VS. o estrangeiro. Reflexões sobre a soberania e a liberalização da imigração, à luz do cosmopolitismo. In: RDCI no 74, 2011, p.289-318.

${ }^{8}$ In: Folha de São Paulo, Caderno Mundo, 6 de abril de 2018, p. A17. 
torcida. Temos que entrar em campo e tratar de marcar gols. Queremos mostrar que somos capazes, trouxemos nossa bagagem e não queremos tirar o lugar dos outros."

Retomando-se a contextualização normativa, no quadro da Lei 13.445/2017 ${ }^{9}$, convém se registrar a revogação da Lei 6815, de 1980 e da Lei 838, de 1949 que disciplinava a requisição da nacionalidade. Em cuidadosos comentários à Lei de Migração, Paulo Henrique Farias Nunes ${ }^{10}$ reconhece a autonomia do campo doutrinário e jurídico do Direito Migratório, em face da pluralidade normativa de fontes que regulam o controle de migrantes, tanto no sistema do direito interno, como no âmbito do direito internacional, ressaltando-se o papel de organismos internacionais, como a OIT, ACNUR, OMI, MERCOSUL.

A estrutura normativa do governo federal centra no Ministério da Justiça a competência para gerenciar questões relacionadas à nacionalidade, naturalização, imigração e estrangeiros, na divisão do Departamento de Migrações, vinculado à Secretaria nacional de Justiça e Cidadania, o Departamento de Polícia Federal e o Comitê Nacional para os Refugiados (CONARE). Integra esse conjunto o Ministério de Relações Exteriores no exercício das funções consulares. E, também, o papel relevante da Defensoria Pública na atuação em processos de repatriação, deportação e expulsão. O retromencionado autor ${ }^{11}$ acentua a importância dos conceitos que distinguem as categorias de imigrante, emigrante, residente, fronteiriço, apátrida e visitante, analisando o $\int 1^{\circ}$ do artigo $1^{\circ}$ da LDM, ressaltando que a condição de refugiado não consta no rol indicado, embora o Estatuto dos Refugiados esteja em vigor no Brasil desde 1954.

9 Brasil, Nova lei de Migração, 2017. Disponível em http://www.planalto.gov.br/ccivil03/ato2015-2018/2017/lei/L13445 html-acesso em 28/09/2019.

${ }^{10}$ Nunes, Paulo H. F. Lei de Migração. Novo Marco Jurídico relativo ao fluxo transnacional de pessoas. Goiânia, Edição do Autor, 2017, p. 21.

11 ob.cit., p. 32. 
Pelas disposições dos artigos $3^{\circ}$ e $4^{\circ}$ da LDM, identificam-se as diretrizes destinadas ao estabelecimento de princípios regentes da política migratória do direito brasileiro, realçando-se a universalidade, a indivisibilidade e a interdependência dos direitos humanos, acolhida humanitária e a garantia do direito à reunião familiar, sendo essa última categorial essencial ao fundamento da dignidade humana e à proteção de fontes convencionais à criança.

No que respeita à retirada compulsória do estrangeiro do território nacional, a LDM contempla os instrumentos da deportação, expulsão e extradição, inovando pela previsão do instituto da repatriação, quando o estrangeiro não obtém autorização para ingresso no território nacional. A extradição pressupõe uma solicitação formal de Estado estrangeiro para processar pessoa acusada ou condenada de crime grave. Trata-se de modalidade associada a prática de tratados ou convenções entre Estados, embora também se caracterize por prática extraconvencional.

O regime jurídico da expulsão protege as relações familiares, tanto na pessoa do filho brasileiro, como do cônjuge ou de qualquer titular de relação jurídico-familiar. Sob esse enfoque mantém aspectos da Súmula $\mathrm{n}^{\circ} 1$ do STF que proibia a expulsão de estrangeiro casado com brasileiro e que tivesse filho dependente de economia paterna. O viés patriarcal desapareceu. Incorporou-se o respeito à dignidade humana, admitindo-se todo e qualquer forma de constituição familiar, sem qualquer manifestação discriminatória. Ademais, o elenco de fatores que possam ensejar a expulsão de estrangeiro circunscreve-se a configurações fáticas tipificadas em modalidades de crimes hediondos e internacionais definidos no Estatuto de Roma do Tribunal Penal Internacional e crimes comuns dolosos a depender da gravidade. Diversamente, o Estatuto do Estrangeiro regulava as hipóteses de expulsão na pessoa do estrangeiro conforme o elenco do artigo 65 da Lei 6815/1980.

Todavia, a partir das análises apresentadas, não se pode olvidar o espaço que a função regulamentar ocupa na esfera da administração pública no direito brasileiro, que se justifica pela necessidade de dinamizar 
exequibilidade aos atos da estrutura administrativa, no universo das normas jurídicas infraconstitucionais, na categoria de resoluções, que, a sua vez, abrangem portarias, alvarás, decretos, avisos ministeriais, que, atribuem competências e procedimentos aos agentes públicos para a execução e implementação dos atos administrativos. E nesse quadro, a Lei de Migração, objeto de aplicação por vários segmentos da organização estatal descerra um conjunto plural de medidas para o controle de migração junto a órgãos tanto da Administração Pública como do Poder Judiciário, além de instâncias oriundas de organizações internacionais e instituições destinadas a garantir proteção ao cidadão migrante. Como a LDM necessita, ainda, de regulamentação pelos vários temas que seu teor normativo engloba, sobreleva-se o risco de prática arbitrárias no preenchimento de lacunas não completadas pelo legislador. Assim, o Decreto federal n ${ }^{\circ} 9.199$, de 20 de novembro de 2017 não contemplou dispositivos que regulem a concessão de vistos humanitários, proteção aos apátridas, situação de migrantes fronteiriços. Thiago Oliveira Moreira ${ }^{12}$ tece críticas à regulamentação, ao identificar incompatibilidades no texto que podem se caracterizar por ilegalidades ensejadoras de vício de inconstitucionalidade, como na hipótese de concessão de visto temporário mediante critério subjetivo de análise pela autoridade competente, de acordo com interesses da política migratória nacional, além de acenar no teor do artigo 211 para decretação de prisão em caso de irregularidade migratória, proibida na LDB, que, na situação aventada, estabelece procedimento administrativo para deportação, retirada ou repatriação.

$\mathrm{E}$ as práticas abusivas parecem não observar os princípios consagrados na LDM, haja vista a entrada em vigor da Portaria $n^{\circ}$ 666, de 25 de julho de 2019, do Ministério da Justiça e Segurança Pública, que regula o impedimento de ingresso, repatriação, deportação sumária, a redução ou

${ }^{12}$ Moreira, Thiago O. A concretização dos direitos humanos dos migrantes pela jurisdição brasileira. $1^{a}$ ed., Curitiba, Instituto Memória Editora. Centro de Estudos da Contemporaneidade, 2019, p.493. 
cancelamento do prazo de entrada de pessoa perigosa para a segurança do Brasil, e, segundo o artigo $2^{\circ}$ dessa norma, consideram-se pessoas perigosas os indicados conforme crimes ali tipificados, sob a rubrica de "suspeitos de envolvimento" nesses delitos. Para tanto, a Procuradoria Geral da República propôs Arguição de Descumprimento de Preceito Fundamental, com pedido de medida cautelar ${ }^{13}$, embasada em potencial violação de direitos fundamentais do migrante, como o princípio do acolhimento, devido processo legal, presunção de inocência e a igualdade entre nacionais e estrangeiros, conforme preceitua a Constituição Federal, além de garantias decorrentes de fontes convencionais ratificados pelo Estado brasileiro.

O Brasil expressa uma vocação democrática no espírito de sua Lei maior e de sua integração no polo internacional e a LDM reerva um nicho significativo de princípios protetivos do migrante, sob a égide do acolhimento, das liberdades, da solidariedade, da autonomia e da dignidade humana, mas as políticas públicas de inclusão social do migrante exigem revisão constante de critérios dogmáticos das diretrizes administrativas na execução e implementação da lei migratória na promoção permanente dos Direitos Humanos, associada a pressões internacionais e à atuação de agências e organizações representantes da sociedade civil.

No último dia 29 do mês de setembro, celebrou-se o $105^{\circ}$ Dia mundial do migrante e Refugiado ${ }^{14}$, homenagem existente desde 1914, em sistema da mobilidade de data. Neste ano, o Papa Francisco abençoou uma escultura dedicada a Migrantes e Refugiados na Praça de São Pedro, no Vaticano, relembrando a Carta aos Hebreus: "Não vos esqueçais da hospitalidade, pela qual, alguns, sem o saberem, hospeda um anjo."

${ }^{13}$ ADPF no 619/2019 - Ministério Público Federal Procuradoria Geral da República.

${ }^{14}$ In: - Vatican News - Acessível: http:/ /www.vatican.news.va/ 


\section{REFERÊNCIAS}

ADPF no 619/2019 - Ministério Público Federal Procuradoria Geral da República.

DOLOWIZ, D. e Marsh, D. "The future of the Policy Transfer research. In: Political Studies Review, 2012, v.10, p.369-345.

DUROSELLE, Jean B. Todo Império perecerá - Teoria das Relações Internacionais. Trad. Ana Eliza S. de Siqueira Magalhães. Brasília, Edlenb, 2000, p.50.

LIMA, Marcelo de. O Estado VS. o estrangeiro. Reflexões sobre a soberania e a liberalização da imigração, à luz do cosmopolitismo. In: RDCI n ${ }^{\circ} 74$, 2011, p.289-318.

$$
\text { . Ob, cit., p. } 32
$$

MACHADO, J. I. Renó. O imigrante e o Estado da diferença. Cátedra da UNESCO. 2015. Memorial da América Latina - S. Paulo.

MOREIRA, Thiago O. A concretização dos direitos humanos dos migrantes pela Jurisdição brasileira, $10^{\mathrm{a}}$ ed. Instituto Memória Editora Centro de Estudos de Curitiba, Contemporaneidade, 2019, p. 493.

SILVA, Tomaz T. (org), Hall, Stuart Woodward, Kathryn. Identidade e Diferença. A perspectiva dos Estados Culturais. Traduções: Tomaz T. da Silva. Petrópolis, Ed. Vozes. 


\section{DELICTAE, Vol. 4, ํㅜ, Jul..-Dez. $2019 \mid 102$}

\section{Internet}

Brasil, Nova lei de Migração, 2017. Disponível em http://www.planalto.gov.br/ccivil03/ato2015-2018/2017/lei/L13445 html-acesso em 28/09/2019.

CULPI, Ludmila A. In http://wwwhumanas..ufpr.br/portal/nepri/files. 2012/04 nova-lei-de-migração $\% \mathrm{C} \% \mathrm{~A} 7 \% \mathrm{C} 3 \%$ BJ es-brasileira Inspira \%Cy.A7\%C3y.30-no-modelo-da-lei-argentina pdf A 30-no In: Folha de São Paulo, Caderno Mundo, 6 de abril de 2018, p. A17.

In: - Vatican News - Acessível: http://www.vatican.news.va/ 
DELICTAE, Vol. 4, №7, Jul..-Dez. $2019 \mid 103$ 